\title{
СОВРЕМЕННЫЕ ПРОБЛЕМЫ ПРИРОДОПОЛЬЗОВАНИЯ БАССЕЙНА ОЗЕРА ХАНКА (В СВЯЗИ С КЛИМАТИЧЕСКИМИ И ГИДРОЛОГИЧЕСКИМИ ИЗМЕНЕНИЯМИ)
}

\author{
Попова А. Ю., Качур А.Н. \\ Тихоокеанский институт географии ДВО РАН, Владивосток \\ anna-41093@mail.ru
}

\begin{abstract}
Аннотащия. Озеро Ханка является самым большим пресноводным водоемом в Северо-Восточной Азии, имеет особый международный статус и является трансграничным. Последние годы наблюдается аномальный подъем уровня воды в озере. Колебания уровня разной периодичности является характерным признаком для многих озёр. Но за последние 5-6 лет повышение уровня воды в озере Ханка привело к подтоплению прибрежных территорий и осложнило хозяйственную деятельность на них. С 2015 года сотрудники Дальневосточного отделения Российской Академии Наук ведут научную дискуссию о том, как изменения водного режима озера Ханка могут повлиять на экосистемы, социальную и экономическую сферы прилегающих к озеру территорий, а также как трансформируются типы природопользования. Природопользование - ключевой момент устойчивого, рационального, сбалансированного, экономически и экологически оптимального развития территории. Бассейн озера Ханка является уникальным в природном, культурно-историческом, социальном и геополитическом плане, в котором на современном этапе происходят климатические и антропогенные изменения. Важными являются процессы, которые протекают на территории северной части озера Ханка и его бассейна. Со стороны Китая наблюдается интенсивное освоение природных ресурсов, высокий уровень антропогенной нагрузки на экосистемы и высокая плотность населения. Механизмы протекания природных процессов распространяются вне зависимости от государственных границ, это является объединяющим фактором трансграничной территории, которая предопределяет ряд особенностей и проблем. В статье рассматривается современная ситуация в бассейне озера как в природном плане, так и в социально-экономическом. Даётся краткий обзор сложившейся проблемной ситуации в бассейне озера Ханка, рассматриваются возможные причины такого положения, а также предлагаются пути наиболее подходящих и рациональных решений этого вопроса.
\end{abstract}

Ключевые слова: трансграничное озеро Ханка, подъём уровня воды, трансформация природопользования, геоэкологические проблемы, климатические и антропогенные изменения. 


\title{
MODERN PROBLEMS OF ENVIRONMENTAL MANAGEMENT OF THE KHANKA LAKE BASIN (WITH CLIMATIC AND HY- DROLOGICAL CHANGES)
}

\author{
Popova A. Y., Kachur A.N. \\ Pacific Geographical Institute FEB RAS, Vladivostok
}

\begin{abstract}
Annotation. Khanka Lake is the largest freshwater reservoir in Northeast Asia. The transboundary lake Khanka (Russia - China) is currently attracting general attention: an abnormal increase in its level occurs, leading to flooding of coastal territories and complicating economic activity on them. This is accompanied by a number of other important processes, in particular, activation of abrasion and waterlogging, changes in the hydrogeological regime and microclimate, transformation of ecosystems, etc. Since 2015, employees of the Far Eastern Branch of the Russian Academy of Sciences have been conducting a scientific discussion on how changes in the water regime of Lake Khanka can affect the ecosystems, social and economic spheres of the territories adjacent to the lake, as well as how environmental management types are transformed. Nature management is a key moment of sustainable, rational, balanced, economically and environmentally optimal development of the territory. The basin of Lake Khanka is unique in its natural, cultural, historical, social and geopolitical plan, in which climatic and anthropogenic changes are taking place at the present stage of conditions. The article discusses the current situation in the lake basin both in the natural plan and in the socio-economic one. A brief overview of the current problem situation in the basin of Lake Khanka is given, possible reasons for this situation are considered, and ways of the most suitable and rational solutions to this issue are proposed.
\end{abstract}

Key words: transboundary Lake Khanka, rising water levels, transformation of nature management, geoecological problems, climatic and anthropogenic changes.

Озеро Ханка - пограничное озеро между Китаем и Россией. Оно является не только самым большим пресноводным водоемом на территории Дальнего Востока России, но и самым большим пресноводным озером на востоке Азии. Озеро Ханка и его бассейн соединяет отдаленные районы двух великих держав: России и Китая. Бассейн оз. Ханка привлекает мировое внимание прежде всего по причине уникального биологического разнообразия.

Озеро Ханка со стороны России имеет 16 притоков: 7 крупных рек - Тур (старое название Турга), Комиссаровка (Синтуха), Ново-Троицкая (Маньчжурка), Мельгуновка (Мо), Рисовая (Хантахеза), Илистая (Лефу), Спасовка (Сантахеза) и 9 небольших речек. Из оз. Ханка вытекает лишь одна р. Сунгач (Сунгача), которая и соединяет озеро с р. Уссури, южным притоком Амура. Со стороны КНР в озеро впадают реки (8): Байлинь (R. Bailin), Хонгунха (C. Hongyanha), Бай- 
пози (C. Baipozi), Цзиньиньку (R. Jinyinku), Чензи (R. Chenzi), Канзи (R. Kanzi), Даксихэ (C. Daxihe), Донгдихэ (C. Dongdihe). Через канал Донгдихэ (С. Dongdihe) в озеро впадает поток из р. Мулинхэ, и это самый большой приток с китайской стороны: $65695\left(10^{4} \mathrm{M}^{3}\right)$ при общем поступлении от всех впадающих рек - $66534\left(10^{4} \mathrm{M}^{3}\right)$. Река Мулинхэ в силу своей протяженности проходит через такие города, как Мулинг, Цзиси, Цзидонг, Мишань и Хулинг [1].

Порядка 91 \% площади водосборного бассейна озера находится на российской стороне. Большую сложность в выделении границ бассейна имеет тот факт, что с китайской стороны с середины $30-$ х годов $\mathrm{XX}$ в. функционируют водорегуляторы для переброса вод из оз. Малая Ханка в р. Мулинхэ и обратно в целях орошения, регулирования уровня воды в озере и т.д. Это тесно связывает бассейн оз. Ханка с бассейном p. Мулинхэ. Отсюда вытекают определенные сложности в научном плане и ряд экологических проблем [3].

Площадь акватории озера меняется в зависимости от уровня воды

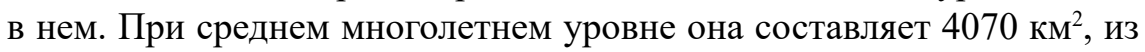

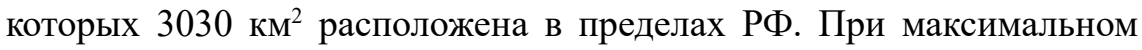

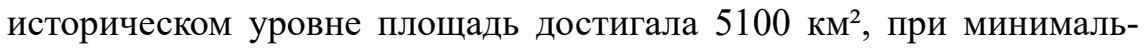
ном - сокращалась примерно до 3800 км² (табл. 1). [4].

В последнее время озеро Ханка является объектом пристального внимания со стороны учёных и общественности из-за нестандартных (по сравнению с последними 100 годами) колебаний уровня воды в озере и затоплений прибрежных территорий, строений, сельскохозяйственных угодий, местообитаний уникальных представителей животного и растительного мира. В связи с серьёзными проблемами, возникающими на данной территории были проведены обзорные экспедиции, предварительные оценки и выдвинуты гипотезы о причинах данного явления. В апреле 2016 г. биолого-почвенным институтом РАН была проведена I Дальневосточная конференция с международным участием «Трансграничное озеро Ханка: причины повышения уровня воды и экологические угрозы» с целью привлечения специалистов из различных областей, сбора имеющейся информации по оз. Ханка и прилегающим территориям, обсуждения, принятия решений, договоренностей и соглашений. Также 14-18 мая 2019 г. была проведена II Всероссийская конференция с международным участием «Трансграничное озеро Ханка: современное состояние и перспективы развития». В конференциях участвовали представители России и 
Китая, что позволило более полно и объективно рассмотреть существующие проблемы на территории двух стран [2].

Таблица 1

Основные морфометрические характеристики озера Ханка и его бассейна [1]

\begin{tabular}{|c|c|}
\hline $\begin{array}{l}\text { Площадь зеркала при высшем уровне без ветровой денивиляции } \\
\text { (390 см) над нулем графика }\end{array}$ & 5010 км $^{2}$ \\
\hline то же при среднем многолетнем уровне (290 см) & 4070 км $^{2}$ \\
\hline то же при низшем уровне (150 см) & 3940 км $^{2}$ \\
\hline Объем воды при высшем уровне & $22,6 \mathrm{\kappa м}^{3}$ \\
\hline то же при среднем многолетнем уровне & $18,3 \mathrm{\kappa M}^{3}$ \\
\hline то же при минимальном уровне & $12,7 \mathrm{\kappa M}^{3}$ \\
\hline Наибольшая длина при среднем многолетнем уровне & 90 км \\
\hline Длина озера по преобладающему направлению ветра (ЮЮЗ) & 87 км \\
\hline Средняя ширина озера & 45 км \\
\hline Наибольшая ширина (по перпендикуляру к продольной оси) & 67 км \\
\hline Средняя глубина при среднем многолетнем уровне & $4,50 \mathrm{M}$ \\
\hline то же при низшем уровне & $3,22 \mathrm{M}$ \\
\hline Наибольшая глубина при среднем многолетнем уровне & $6,50 \mathrm{M}^{*}$ \\
\hline Длина береговой линии при среднем многолетнем уровне & 308 км \\
\hline Коэффициент развития береговой линии & 1,36 \\
\hline Площадь бассейна (без зеркала озера) & 16890 км $^{2}$ \\
\hline то же без бассейна озера Малая Ханка & 15820 км$^{2}$ \\
\hline Доля площади водоема от площади бассейна (без оз. М. Ханка) & $25,7 \%$ \\
\hline $\begin{array}{l}\text { Отношение объема озера (при среднем многолетнем уровне) к } \\
\text { годовому притоку воды }\end{array}$ & 9,4 \\
\hline $\begin{array}{l}\text { Отношение объема озера (при среднем многолетнем уровне) к } \\
\text { годовому стоку воды }\end{array}$ & 9,9 \\
\hline
\end{tabular}

* - максимальная глубина по данным (1998 г) - 11, 6 м.

Гидрологический режим озера Ханка, его ёмкостные характеристики определяют природные и антропогенные факторы. К природным факторам можно отнести атмосферные осадки, речной сток, испарение с водной поверхности озера. К антропогенным факторам относятся хозяйственная деятельность на водосборной площади озера и переброска стока [9]. Как сказано выше, водосбор трансграничного озера Ханка расположен на территории Приморского края России (большая часть) и провинции Хейлунцзян Китая. Вытекающая из озера р. Сунгача является притоком трансграничной р. Уссури, которая впадает в р. Амур в районе г. Хабаровск. Значительный вклад в аномальный рост уровня озера Ханка дает переброска сто- 
ка р. Мулинхэ в бассейн озера Малая Ханка и затем в озеро Ханка (рис. 1) [5].

Подъём уровня воды в озере на 1,2 м в течение нескольких лет привёл к различным последствиям для его восточных и западных берегов. На западном побережье в районе от села Турий-Рог до Камень-Рыболова абразивно-денудационные и абразивные процессы с максимальной эрозией берегов проявились наиболее интенсивно. На восточном побережье произошло в основном затопление территории и повышение уровня грунтовых вод. Разрушение побережья продолжается в результате оползневых процессов и проявлений плоской и линейной эрозии на уступах $[2,9]$. При пересчете осадков в объемных единицах $\left(\kappa^{3}\right)$ с использованием площади зеркала озер Ханка и Малая Ханка при среднемноголетнем уровне получим представление о масштабах прихода влаги в озеро из атмосферы. Средний объем осадков на озеро составляет 2,45 км³. Доля этого прихода в общем объеме озера составляет в среднем около $13 \%$. Средние характеристики годовых осадков по этим станциям за 1981-2010 гг. изменились всего на 1-4 мм, а средние месячные - на 0-8 мм [5].

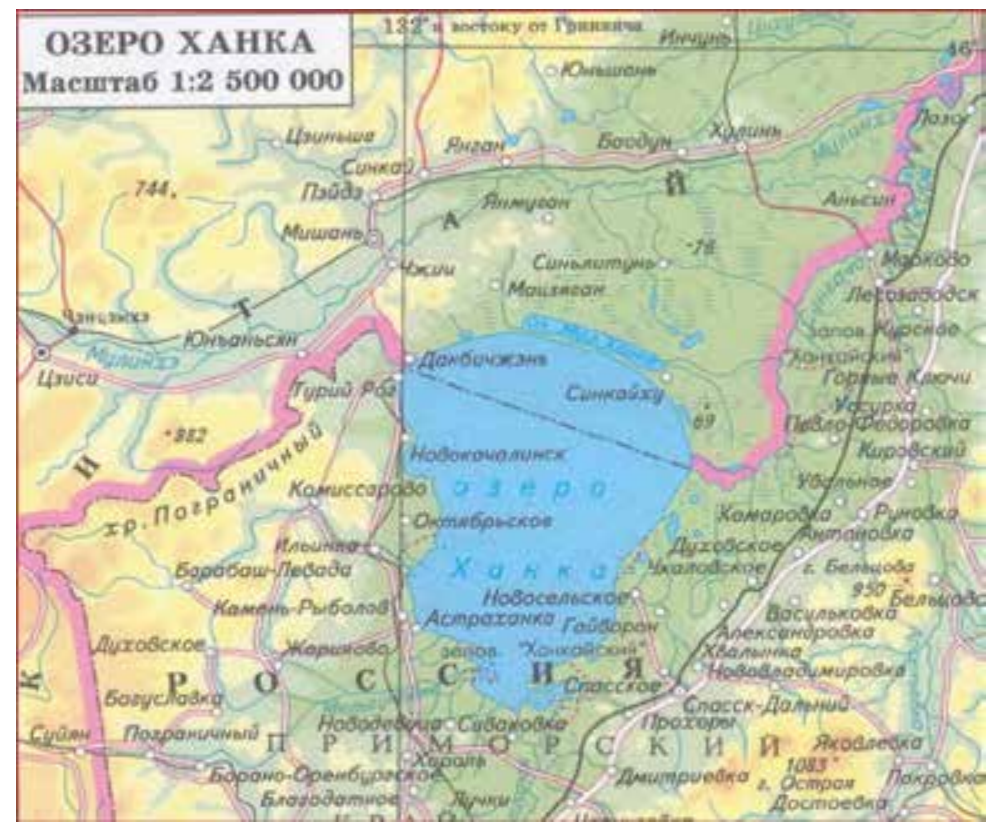

Рис. 1. Озеро Ханка [5] 
Высокая аномалия осадков наблюдалась на юге Приморского края России в 2015-2016 гг. В конце августа 2015 года и летом 2016 года после прохождения тайфуна «Гони» на юге Приморского края 26 августа 2015 года наблюдалось значительное повышение уровня воды в озере Ханка. Повышение уровня озера и затопление прилегающих земель продолжалось до лета 2016 года и продолжается последнее время, что больше не связано с прохождением сильных тайфунов. Это в основном связано как с экстремальным увеличением количества осадков осенью 2015 года, так и с снегом зимой 2016 года в бассейне озера Ханка, особенно над Пограничным хребтом, и положительной десятилетней аномалией среднего количества осадков с января по август в течение предыдущего долгосрочного периода 2004-2015 годов (по данным Пономарева В.) (ТОИ ДВО РАН) $[1,10]$. Также происходят трансформации экосистем в условиях изменения климата, всё это наносит не только экологический, но и экономический ущерб населению, а также предприятиям и населённым пунктам на прилегающих к озеру территориях [10].

В последние 10 лет в режиме уровня оз. Ханка наметилась тенденция его непрерывного повышения (рис. 2) [6]. В целом же на данный момент точная причина такого повышения уровня озера не установлена. Существует ряд мнений и гипотез, но для более конкретных выводов требуются дополнительные исследования и взаимообмен данными с китайской стороной [2]. Для предотвращения ухудшения ситуации необходимо наметить основные варианты мероприятий по регулированию уровня озера, например:

- сокращение переброски части стока р. Мулинхэ в Малую Ханку;

- на основе учета климатических изменений рассмотреть варианты изменения системы природопользования в бассейне;

- определить нормы безвозвратных изъятий вод в бассейне для нужд экономики и населения [7].

Проблемы совместного водопользования в трансграничных бассейнах с КНР существенны. Например, известно, что забор воды на китайской стороне около 40 раз превосходит забор на российской стороне Амура [8]. Но далеко не все для нас ясно, так как китайская сторона не дает детальной информации. В нашем случае пока остается неизвестным сколько воды может Китай единовременно сбросить в Ханку или сколько воды находится у них в каналах и водохранилищах. Известно, что на нашей стороне нет таких водохранилищ, 


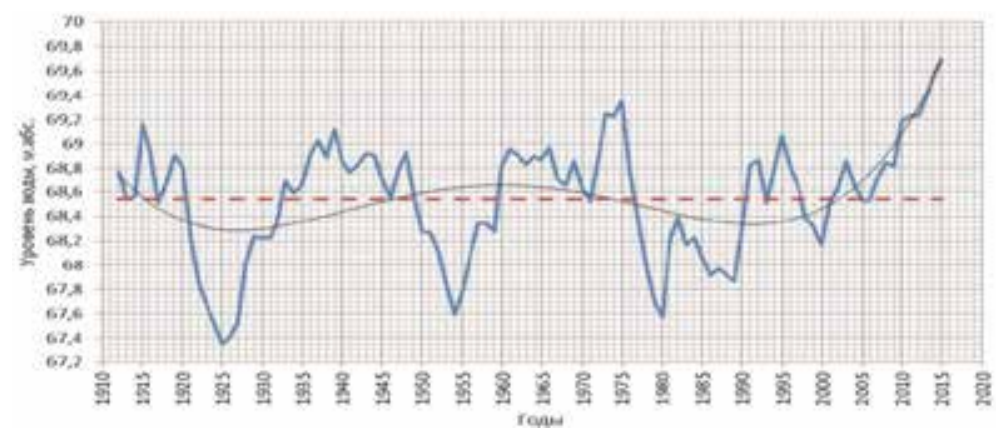

Рис. 2. Динамика среднегодового уровня воды в озере Ханка [6]

которые могли бы так глобально влиять на гидрологический баланс озера.

В целом, как мы видим, экологическая ситуация в бассейне оз. Ханка не является благополучной. Неочищенные сточные воды промышленных и сельскохозяйственных предприятий являются ведущим антропогенным фактором, влияющим на экологическую обстановку в бассейне оз. Ханка. Особую угрозу биоте данной территории и проживающему здесь населению составляют сбросы воды с участков рисосеяния (табл. 2) [4].

Таблица 2

Геоэкологические проблемы в бассейне озера Ханка [4]

\begin{tabular}{|c|c|c|}
\hline \multirow{2}{*}{$\begin{array}{c}\text { Основные } \\
\text { геоэкологические } \\
\text { проблемы }\end{array}$} & \multicolumn{2}{|c|}{ Основные факторы геоэкологических проблем } \\
\hline & В озере & В бассейне \\
\hline Подъём уровня воды & $\begin{array}{l}\text { Береговая эрозия, оползни, } \\
\text { приток дополнительных } \\
\text { осадков в озеро }\end{array}$ & $\begin{array}{l}\text { Затопление прибрежных } \\
\text { территорий, подъем } \\
\text { уровня грунтовых вод, } \\
\text { заболачивание }\end{array}$ \\
\hline $\begin{array}{l}\text { Понижение уровня } \\
\text { воды }\end{array}$ & $\begin{array}{l}\text { Формирование } \\
\text { прибрежного рельефа } \\
\text { (прибрежные отложения, } \\
\text { мелководье и т. д.) }\end{array}$ & $\begin{array}{l}\text { Появление новых форм } \\
\text { прибрежного рельефа с } \\
\text { первичной растительностью, } \\
\text { включая изолированные } \\
\text { лагуны; активация эоловых } \\
\text { процессов }\end{array}$ \\
\hline $\begin{array}{l}\text { Загрязнение воды } \\
\text { и прибрежных } \\
\text { экосистем }\end{array}$ & $\begin{array}{l}\text { Ухудшение качества воды } \\
\text { в устьях и прибрежной } \\
\text { зоне, загрязнение } \\
\text { гидробионтов, в том числе } \\
\text { промысловых рыб }\end{array}$ & $\begin{array}{l}\text { Загрязнение воздуха, почв и } \\
\text { рек, впадающих в озеро (в } \\
\text { том числе трансграничных) }\end{array}$ \\
\hline
\end{tabular}


Кроме того, сети водоснабжения и водоотведения жилого сектора ряда населенных пунктов, значительно изношены, что влечёт случаи разливов канализационных стоков на поверхность почвы, попадание их в ручьи, несущие свои воды в оз. Ханка.

Являясь трансграничным, оз. Ханка принимает загрязняющие вещества как от российской части, так и от китайской части водосборного бассейна. В настоящее время на китайской части бассейна сильно развито сельское хозяйство, особенно выращивание риса. Применяются пестициды и удобрения, что приводит к загрязнению окружающей среды. По данным оценки качества поверхностных вод в Китае в 2005-2010 гг. в реках северо-восточной части Китая было отмечено увеличение концентрации ионов аммония, что может усиливать эвтрофирование водных объектов [4].

Вследствие этого необходимо продолжать проведение специальных работ, мониторинга, составление рекомендаций и планов, имеющих под собой научную основу в рамках выполнения проектов с целью перехода к действительно рациональному природопользованию и устойчивому развитию, а не только к полному освоению территории и ресурсов, а также во избежание проблем природопользования, вызванных природными факторами. А также в рамках трансграничной территории бассейна необходимо разработать и реализовать специальную международную российско-китайскую программу развития бассейна оз. Ханка с учетом интересов обеих сторон [2].

Причина повышения уровня воды в озере Ханка комплексная и, вероятно, заключается в наложении нескольких явлений: естественного многолетнего цикла озера в условиях юга Дальнего Востока, климатических изменений в регионе, межбассейновой переброски вод из р. Мулингхэ. Также здесь возможен некоторый вклад и других факторов.

Рассмотренные процессы, в первую очередь гидрологические и климатические, отрицательно сказываются на природопользовании в бассейне оз. Ханка. Аномальная ситуация с подъемом уровня воды в озере является основанием для корректировки проводимой политики, пересмотра плана развития территории с учетом различных сценариев дальнейшего развития событий - как для варианта повышения уровня или его стабилизации, так и для его понижения. Очевидно, что при первом варианте будут затоплены поймы рек, а также под воду могут уйти первые террасы озера. 
Помимо внутригосударственной интеграции и объединения усилий научных организаций, проводящих исследования озера, необходимо проведение совместных международных российско-китайских исследований, а также разработка и реализация плана развития и управления устойчивым природопользованием трансграничного бассейна оз. Ханка.

Научный руководитель: зав. Центра ландшафтно-экологических исследований ТИГ ДВО РАН; Руководитель работ по международным проектам, директор иентра NOWPAP POMRAC, к.г.н. Качур A.H.

\section{Литература}

1. Ананьева Е.Е., Бакланов П.Я., Качур А.Н. Проблемы озера Ханка и его бассейна на рубеже столетий // Трансграничное озеро Ханка: причины повышения уровня воды и экологические угрозы. Материалы I Дальневосточной конф. 27-29 апреля 2016 г. / ред. Ю.Н. Журавлёв, С.В. Клышевская. Владивосток: Дальнаука, 2016. C. $12-25$.

2. Ананьева Е.Е. Современная ситуация в бассейне оз. Ханка // Географические и геоэкологические исследования на Дальнем Востоке: сб. научных статей молодых ученых. Вып. 12. Владивосток, 2016. С. 29-34.

3. Ананьева Е.Е. Озеро Ханка: Колебания уровня и их причины // Астраханский вестник экологического образования. 2016. № 4. С. 48-57.

4. Бакланов П.Я., Качур А.Н., Ермошин В.В., Коженкова С.И., Бугаец А.Н., Базарова В.Б., Махинов А.Н., Ким В.И., Шамов В.В. Современные геоэкологические проблемы озера Ханка и пути их решения. / Доклад на II Всероссийской конференции с международным участием «Трансграничное озеро Ханка: современное состояние и перспективы развития», Владивосток 14-18 мая 2019 г.

5. Бортин Н.Н., Горчаков А.М., Кролевецкая Ю.В. Антропогенные мероприятия в бассейне оз. Ханка, как основной фактор нарушения его водного режима / Доклад на II Всероссийской конференции с международным участием «Трансграничное озеро Ханка: современное состояние и перспективы развития», Владивосток 14-18 мая 2019 г.

6. Бортин Н.Н., Горчаков А.М. Анализ факторов неустойчивости водного режима оз. Ханка и предлагаемых путей решения проблем // Трансграничное озеро Ханка: причины повышения уровня воды и экологические угрозы. Материалы I Дальневосточной конф. 27-29 апреля 2016 г. / ред. Ю.Н. Журавлёв, С.В. Клышевская. Владивосток: Дальнаука, 2016. С. 31-41.

7. Болгов М.В. О причинах и вероятностном прогнозе экстремальных уровней воды в трансграничном озере Ханка / Доклад на II Всероссийской конференции с международным участием «Трансграничное озеро Ханка: современное состояние и перспективы развития», Владивосток 14-18 мая 2019 г.

8. Журавлёв Ю.Н. Озеро Ханка - крупнейшее водохранилище Приморского края и Южного Сихотэ-Алиня / Доклад на II Всероссийской конференции с международ- 
ным участием «Трансграничное озеро Ханка: современное состояние и перспективы развития», Владивосток 14-18 мая 2019 г. 9. Махинов А.Н., Ким В.И., Матвиенко Д.В. Абразивно-аккумулятивные процессы на берегу озера Ханка с высоким уровнем воды / Доклад на II Всероссийскую конференцию с международным участием «Трансграничное озеро Ханка: современное состояние и перспективы развития» 1418 мая, Владивосток 2019

10. Пономарёв, В., Дмитриева, Е., Шкорба, С. Особенности аномалий погоды на Дальнем Востоке России в 21 веке, связанные с изменением планетарного климатического режима / Доклад на II Всероссийской конференции с международным участием «Трансграничное озеро Ханка: современное состояние и перспективы развития», Владивосток 14-18 мая 2019 г.

\section{References}

1. Ananyeva E.E., Baklanov P.Ya., Kachur A.N. [Problems of Lake Khanka and its basin at the turn of the century] Materialy I Dal'nevostochnoj konferencii «Transgranichnoe ozero Hanka: prichiny povysheniya urovnya vody i ekologicheskie ugrozy» [Transboundary Lake Khanka: causes of rising water levels and environmental threats. Proc. of the I ${ }^{\text {st }}$ Far Eastern Conf.]. Eds.: Yu.N. Zhuravlev, S.V. Klyshevskaya. Vladivostok, Dalnauka Publ., 2016, pp. 12-25.

2. Ananyeva E.E. [The current situation in the lake basin Khanka]. Geograficheskie $i$ geoekologicheskie issledovaniya na Dalnem Vostoke_sb. nauchnih statei molodih uchenih [Geographical and geoecological studies in the Far East: collection of scientific articles of young scientists]. Vladivostok, 2016, vol. 12, pp. 29-34.

3. Ananyeva E.E. Ozero Hanka: Kolebaniya urovnya i ih prichini [Khanka Lake: Level Fluctuations and Their Causes]. Astrahanskii vestnik ekologicheskogo obrazovaniya - Astrakhan Bulletin of Environmental Education. 2016. no. 4, pp. 48-57.

4. Baklanov P.Ya., Kachur A.N., Ermoshin V.V., Kojenkova S.I., Bugaec A.N., Bazarova V.B., Mahinov A.N., Kim V.I., Shamov V.V. [Modern geoecological problems of Lake Khanka and ways to solve them]. Report at the $2^{\text {nd }}$ All-Russian Conference with International Participation "Transboundary Lake Khanka: current status and development prospects", Vladivostok, May 14-18, 2019. (In Russian, unpublished).

5. Bortin N.N., Gorchakov A.M., Krolevetskaya Yu.V. [Anthropogenic measures in the lake basin Khanka: current status and development prospects]. Report at the $2^{\text {nd }}$ All-Russian Conference with International Participation "Transboundary Lake Khanka: current status and development prospects", Vladivostok, May 14-18, 2019. (In Russian, unpublished).

6. Bortin N.N., Gorchakov A.M. [Analysis of factors of instability of the water regime of Lake Khanka and proposed solutions to problems]. Materialy I Dal'nevostochnoj konferencii «Transgranichnoe ozero Hanka: prichiny povysheniya urovnya vody $i$ ekologicheskie ugrozy" [Transboundary Lake Khanka: causes of rising water levels and environmental threats. Proc. of the I ${ }^{\text {st }}$ Far Eastern Conf.]. Eds.: Yu.N. Zhuravlev, S.V. Klyshevskaya. Vladivostok, Dalnauka Publ., 2016, pp. 31-41.

7. Bolgov M.V. [On the causes and probabilistic forecast of extreme water levels in the transboundary Lake Khanka]. Report at the $2^{\text {nd }}$ All-Russian Conference with International Participation "Transboundary Lake Khanka: current status and development prospects", Vladivostok, May 14-18, 2019. (In Russian, unpublished). 
8. Juravlev Yu.N. [Khanka Lake - the largest reservoir of the Primorsky Territory and Southern Sikhote-Alin]. Report at the $2^{\text {nd }}$ All-Russian Conference with International Participation "Transboundary Lake Khanka: current status and development prospects", Vladivostok, May 14-18, 2019. (In Russian, unpublished).

9. Mahinov A.N., Kim V.I., Matvienko D.V. [Abrasive-accumulative processes on the shore of Lake Khanka with a high water level]. Report at the $2^{\text {nd }}$ All-Russian Conference with International Participation "Transboundary Lake Khanka: current status and development prospects", Vladivostok, May 14-18, 2019. (In Russian, unpublished).

10. Ponomarev V., Dmitrieva E., Shkorba S. [Features of weather anomalies in the Russian Far East in the 21st century associated with a change in planetary climate regime]. Report at the $2^{\text {nd }}$ All-Russian Conference with International Participation "Transboundary Lake Khanka: current status and development prospects", Vladivostok, May 14-18, 2019. (In Russian, unpublished). 